\title{
Resident Non-visitation to a National Museum Site: \\ The Steven F. Udvar-Hazy Center
}

Laura Lawton, Griffith University, Gold Coast, Queensland, Australia

and Margaret Daniels, George Mason University, Manassas, VA, USA

\begin{abstract}
Resident non-participation is a major contemporary issue for the Steven F. Udvar-Hazy Center (Udvar-Hazy Center), a recently opened companion facility to the Smithsonian Institution's National Air and Space Museum on the National Mall. The current study investigates the motivations and characteristics of local non-visitors. Residents from three surrounding counties comprised the study population and, as part of the larger study, responded to statements pertaining to reasons for non-visitation to the Udvar-Hazy Center, derived and modified for a museum context from the leisure constraints literature. Analysis of non-visitors, about one-half of the sample, resulted in the identification of relatively homogenous minimally-constrained, awareness-constrained, time-constrained and access-constrained clusters. Managerial implications of these findings are considered.
\end{abstract}

Keywords: museums, museum visitation, community tourism, cluster analysis, residents, sustainability, Smithsonian 


\section{INTRODUCTION}

Audience development is described by Kotler and Kotler (1998) as a primary objective of contemporary museums, especially given a recent pattern in countries such as the United States of stagnant or declining visitation, a parallel pattern of increasing reliance on visitor-based revenues, and increased emphasis on a policy of 'access for all' that implies optimal participation of local residents as well as tourists (Mylonakis \& Kendristakis, 2006). Audience development is a major contemporary issue for the Steven F. Udvar-Hazy Center (Udvar-Hazy Center) in the Virginia suburbs of Washington, DC, a recently opened companion facility to the Smithsonian Institution's National Air and Space Museum (NASM) on the National Mall. Of concern to the managers of this facility is a pattern of declining visitation, as described below. Part of the evolving strategy to reverse this pattern of decline is to increase the number of visits from local residents, who are not patronizing the facility at levels initially anticipated by its management.

The overall goal of this article is to provide rigorous knowledge about the phenomenon of major facility non-visitation among local residents, utilizing the Udvar-Hazy Center as a case study. More specifically, the paper identifies

- the proportion of local residents that has not visited the Udvar-Hazy Center

- reasons for non-visitation

- demographic and other relevant characteristics that differentiate local visitors from local non-visitors 
- significant segments within the non-visitor cohort in terms of reasons for not visiting, and

- demographic and other relevant characteristics that differentiate these segments.

The article concludes by considering the managerial implications of these findings for the Udvar-Hazy Center and for major regional museums more generally. Sections on museum visitation trends, methodology and study results precede this discussion.

\section{MUSEUM VISITATION TRENDS}

During the past two decades, stagnant visitation levels have been noted at museums and other cultural sites throughout the United States (Bryan, 2004; Tian, Crompton, \& Witt, 1996), with median annual attendance at the nation's 17,500 museums remaining steady at 34,000 during the early 2000 s (American Association of Museums, 2006). This lack of growth has been attributed to such diverse factors as the increase in the number of such attractions (i.e. the dilution effect), competition from a more diverse array of leisure activities, and economic and political uncertainty particularly in the wake of the 2001 terrorist attacks. It is alleged additionally that many museums experience stagnation because of their failure to 'turn over' displays and programs more frequently or to emphasize story-telling, entertainment, hands-on interaction, and other forms of stimulation that engage a more diverse array of consumers and encourage repeat visitation (Graburn, 1998; Hudson, 1998; Schouten, 1998; Yeh \& Lin, 2005). Another 
possible factor is an emphasis on attractions that focus on the heritage and experience of people of European descent who comprise a declining share of the national population (Tian, Crompton, \& Witt, 1996).

Stagnant or declining visitation has substantial negative implications for museums given the parallel reality of increased operating costs and decreased funding from traditional sources such as government and foundations. Funding from these latter sources may erode further as museums are perceived to be alienated from the increasingly diverse public they supposedly serve, while concurrently this same public is becoming more important as a funding source in its own right, often through donations and the purchase of ancillary products if not through entrance fees. Geissler, Rucks and Edison (2006), accordingly, call for museums to adopt more of a marketing approach to their management and strategic planning that includes attention to comprehensive audience recruitment and retention.

\section{Visitation by Local Residents}

Audience cultivation strategies are often based on the fundamental distinction between local resident and tourist segments, with the latter being important because of its enormous potential and its association with the generation of outside revenue. Local residents are an important complement to this flow of tourists, providing a vital source of visitors to museums and other attractions especially during the tourism off-season. More so than tourists, local residents can take advantage of their spatial proximity to visit more frequently 
and more spontaneously - thus compensating for lower expenditures per visit (Kotler \& Kotler, 1998), and may develop a stronger sense of loyalty toward and support for 'their' local museum. They also function as ambassadors and tour guides who facilitate visits to attractions by visiting friends and relatives. More broadly, the long-term success of a destination's tourism base is increasingly seen as being associated with a mutually beneficial 'community-based' approach that includes broad-based community access to and interaction with local attractions (Singh, Timothy, \& Dowling, 2003).

Despite the importance of the local community to museums and affiliated facilities, related academic investigations are limited. The importance of the community-based approach is recognized by Xie (2006), who warned that local residents in Toledo, Ohio were not strongly supportive of a proposed Jeep museum due to concerns about authenticity and location. Hood (1983), in a related study, found that $46 \%$ of Toledo area residents were 'nonparticipants' who never visited area museums. Nonparticipants tended to be sociable individuals who were uncomfortable in such venues, which they regarded as inaccessible and unfamiliar. Falk (1993) reviewed a number of anecdotal studies and similarly found that nonparticipants typically constitute around one-half of a given local population. Such individuals tend to have lower levels of education and income, and are over-represented among non-white racial groups (Kotler \& Kotler, 1998).

\section{Constraints to Visitation}


Beyond the macro factors described above that have been proffered as reasons for stagnant museum visitation, it is particularly useful to consider the related or unrelated reasons for nonparticipation, or 'constraints' to same (Jackson, 1988) that actually pertain to any given individual. A topic that has received substantial attention within the leisure and recreation literature (Jackson, 2005), constraints are commonly categorized as 'intrapersonal' (e.g., stress, perceptions of safety and crowding, level of skills, health, disability, lack of awareness, lack of interest), 'interpersonal' (e.g., lack of appropriate partners, lack of family support), and 'structural' (e.g., cost, presence of small children in the household, insufficient time, lack of transport) (Crawford, Jackson, \& Godbey, 1991).

Empirically, Nadirova and Jackson (2000) surveyed a sample of Canadian households and identified five broad constraint domains that limited participation in leisure and recreation activities, i.e. 'isolation' (e.g., lack of safety, lack of transportation), 'knowledge' (e.g., lack of information), 'skills' (e.g., disabilities, discomfort in social settings), 'costs' (e.g., admission fees) and 'commitments' (e.g., lack of time). With specific reference to museums, a study of mainly local visitors at five facilities in Galveston, Texas revealed excessive cost, lack of time, difficulty of access, repetition, product failings and lack of interest as the main constraint domains (Tian, Crompton, \& Witt, 1996).

\section{Case Study}


The 176.5-acre Udvar-Hazy Center complex opened December 15, 2003 on the grounds of the Washington Dulles International Airport in Chantilly, Virginia. Built at a cost of $\$ 311$ million, the site is intended to eventually exhibit $80 \%$ of the national air and spacecraft collection, with an additional $\$ 90$ million being required to provide 'phase two' capacity for this purpose. The suburban location of the Udvar-Hazy Center is unusual because of its spatial disconnect from the major tourist districts of downtown Washington. Disadvantages of access associated with this peripherality, however, are outweighed by the provision of sufficient space for present and future exhibition needs as well as parking, access to an active runway, and support from the Commonwealth of Virginia.

At the time of opening, a sustained level of three million annual visits was projected (Smithsonian National Air and Space Museum, 2003), based perhaps on the increasing popularity of air and space museums as repositories of iconic aircraft and manifestations of the nation's technological and military prowess (Fopp, 1997). Instead, visitation steadily declined from an estimated 1,491,000 in fiscal 2004 to $1,261,000$ in fiscal 2005 and 1,020,000 in fiscal 2006 (Smithsonian Institution, 2007a). Smithsonian officials have attributed this decline at least in part to the erosion of the novelty effect (Smithsonian Institution, 2007b), but this alone does not appear to adequately account for the considerable discrepancy between the projected and actual visitation.

This pattern of declining visitation represents a major challenge for UdvarHazy Center management, which is particularly dependent on visitor-related 
revenues to offset debt since federal appropriations were confined to the design phase and did not support construction efforts (Ezell, 2004). Although there is no entrance fee, an on-site parking fee of $\$ 12$ is charged per vehicle, and additional revenues are obtained from a souvenir shop, an IMAX theater and the museum's café. One important dimension of this issue is the need to increase the number of visits from local residents, especially given the site's relative inaccessibility to tourists and the rapid growth of the local population base.

\section{METHODS}

Data were collected from November 2005 until November 2006. One thousand households from each of three counties closest to the museum (Prince William, Fairfax and Loudoun) were randomly selected from relevant online telephone directories to receive a mail-out survey packet. Each packet contained a cover letter and fact sheet about the Udvar-Hazy Center, two versions of the five-page questionnaire, a prize distribution entry form (respondents timely submitting a fully completed questionnaire were eligible for a cash draw) and a postage paid return envelope.

Version 1 of the questionnaire was intended for residents who had never previously visited the museum. Items in Version 1 pertained to reasons for nonvisitation, specific interest in visiting the Udvar-Hazy Center in the future as well as intention to visit, interest in and knowledge of air and space, specific program requests, general involvement in museum visitation, desired services and features of museums in general and demographic information. Eighteen 
statements pertaining to the reasons for the respondent's non-visitation to the Udvar-Hazy Center were included, derived and modified for a museum context from the leisure constraints literature. Each statement was assessed on a 1-to-5 scale, from 'no influence' (1) to 'slight influence' (2), 'some influence' (3), 'strong influence' (4), and 'very strong influence' (5).

Version 2 of the questionnaire contained questions for residents who had previously been to the museum. Items in Version 2 pertained to satisfaction with most recent visit, specific interest in visiting the Udvar-Hazy Center again as well as intention to revisit, interest in and knowledge of air and space, specific program requests, general involvement in museum visitation, desired services and features of museums in general and demographic information.

In the common cover letter, residents were requested to have one adult member of the household fill out and return the version of the questionnaire that applied to that individual. Only one questionnaire per household was to be returned. To avoid confusion, the questionnaires were color-coded (yellow for non-visitors, green for prior visitors) and clearly labeled to the intended audience. One week after the initial mailing, residents received a follow-up reminder postcard and information regarding how to obtain a second survey package if the first had been discarded or misplaced.

The focus of this paper is on the results of the non-visitor survey, with comparisons made, as appropriate, with visitors. The intent was first of all to calculate means for each of the 18 'reasons for nonvisitation' statements in order to identify the overall importance of each. Subsequently, the statements, or some 
sub-set thereof, was cluster analyzed to identify relatively homogenous subgroups of the overall non-visitor sample. It cannot be assumed that 'natural' subgroups exist within the target population, but the segmentation of populations without such groupings is still legitimate and preferable to treating these populations as undifferentiated mass markets (Dolnicar \& Leisch, 2008; Mazanec et al., 1997). Hierarchical cluster analysis, using Ward's method, is frequently used to achieve this objective (Hair et al., 1995). A range of solutions (for example, two to five clusters) is usually requested, and the most sensible solution accepted after considering for each option the respective dendograms, cluster sizes, differences in statement means between the clusters, and interpretability. Some applications subject the original statements (especially if they are numerous) to factor analysis in order to obtain the underlying dimensions and then perform cluster analysis on the resulting factor scores. However, in this case the number of statements $(n=18)$ is not excessively large, and we further concur with Hair et al. (1995) that this approach may not adequately represent the variables that actually discriminate between the underlying groups. It is worth bearing in mind, particularly in the absence of natural population subgroups, that there is no definitive 'right' or 'wrong' solution in cluster analysis, which is often described as an art as much as a science.

The non-visitor questionnaire also solicited information about the respondents' residence, age, gender, race, marital status, household income and employment status. Comparison-of-means tests and chi-squared tests, as appropriate were employed to identify significant differences first of all between 
visitors and non-visitors, and then between the non-visitor clusters once a solution had been accepted.

\section{RESULTS}

A sample of 422 adults (228 who had previously visited the Udvar-Hazy Center and 194 who had not) completed usable questionnaires, while an additional 82 were returned unusable, either due to incorrect addresses or incomplete information provided. The adjusted response rate was $14.5 \%$. This low relative yield appears to be increasingly normative in contemporary social science research (Dey, 1997; Oppermann, 2000). However, more importantly, enough surveys were received to perform cluster analysis, which requires at least five cases (i.e., respondents) per item (Hair et al., 1995). Specifically, 192 of the 194 surveys returned by the Udvar-Hazy Center non-visitors yielded completed response sets to the statements pertaining to reasons for their nonvisitation.

Of more concern is non-response bias as indicated by the underrepresentation of respondents of diverse racial backgrounds that reside in the counties surrounding the museum. While residents with ethnic origins including African American, Asian, Hispanic/Latino, Middle Eastern and Native American accounted for approximately $40 \%$ of the study area population in 2006 (U.S. Census Bureau, 2006) only $16.3 \%$ of the survey respondents were from these representative groups. Allowing for a more youthful demographic profile, adults with these cultural backgrounds would still account for about one-third of 
the total adult population in the study area. Data weighting of minority respondents to take into account this underrepresentation, however, was rejected since this might accord false representation to the results provided by the small actual number of minority respondents. Household income was more representative, with a median of $\$ 110,000$ obtained from both the survey and the U.S. Census Bureau (2006) community survey.

\section{Visitors vs. Non-visitors}

Forty-six per cent of the local resident sample had not previously visited the Udvar-Hazy Center, and this segment differed significantly from prior visitors in terms of race, but not age, sex or household income. Specifically, the nonvisitor component increased to $64.7 \%$ among non-white residents, compared with $42.2 \%$ for non-Hispanic whites (Table 1). Non-visitors also reported a significantly smaller number of visits, on a yearly basis, to other museums and/or cultural attractions (a mean of 4.05 vs. 5.28). None of the 18 provided reasons for non-visitation yielded an overall mean above the midpoint of 3.00 , while insufficient time (2.80) and perceptions of a high parking fee (2.72) were the only two that approached this threshold (Table 2). Fourteen of the items ranged between overall means of one ('no influence') and two ('slight influence'), further indicating, overall, a relatively unconstrained sample of non-visitors. However, it is notable that three of the four items that exceeded a mean of two were related to time (i.e., insufficient time, excessive work commitments, and conflicting schedules with family/friends). When asked whether they intended to visit the 
Udvar-Hazy Center within the next three months, $37.6 \%$ of the non-visitor segment replied affirmatively.

(Tables $1 \& 2$ here)

\section{Non-visitor Clusters}

After analyzing combinations of solutions ranging from two to four clusters and 14 to all 18 of the statements, a four-cluster/14 statement option was selected as being the most amenable to interpretation and the most internally reliable with an acceptable Cronbach's alpha value of .737. Three statements ('I have no one to go with', 'I am in poor health' and 'physical barriers make visitation difficult') were eliminated because they yielded small standard deviations and failed to differentiate the clusters for any of the solutions investigated where they were included. A fourth statement, 'I have no interest in air and space history', was omitted because it consistently yielded weaker differences between the clusters when included in solutions. The F-tests for the 14 retained statements were all significant at the 95\% level (Table 3).

(Table 3 here)

Analysis of these clusters reveals significant variation in terms of the constraints that are most pertinent. For example, the largest group, consisting of $52.6 \%$ of the non-visitor segment or 102 respondents, regarded most of the 
factors as not being especially influential, and especially differs from the remaining clusters in perceiving work commitments as a non-constraint. Only the high parking fee is close to being regarded as having 'some influence' in members' non-visitation. Appropriately, the members of this cluster are described as the 'minimally-constrained'. The second cluster, consisting of just 22 respondents (or $11.5 \%$ of the non-visitor segment), is distinguished by the strong to very strong influence of never having previously heard of the Udvar-Hazy Center, a factor which is minimally evident in the other clusters. The other responses of these 'awareness-constrained' non-visitors, accordingly, may indicate generic constraints applicable to all such attractions and/or may reflect responses to new information transmitted by the questionnaire. It is notable that the awareness-constrained are the only non-visitors to rate lack of interest in air and space history as having at least a 'slight influence' on their non-visitation (mean $=2.23$ ), which may help to account for their lack of awareness about the Center.

The third cluster, accounting for $13.5 \%$ of non-visitors (or 26 individuals), was significantly differentiated from all the remaining clusters only on the three statements related to time, and members are therefore described as 'timeconstrained'. Finally, 43 non-visitors (22.4\% of all non-visitors) are significantly differentiated mainly by factors related to distance, location, proximity to other attractions, and traffic conditions. The subsequent description of members as 'access-constrained' is corroborated by the especially strong influence of high parking fees. Although not always at a statistically significant level, it is notable 
that this cluster yielded the highest means on all statements except those pertaining to insufficient time, and lack of awareness about the Udvar-Hazy Center.

As depicted in Table 4, the clusters differ significantly on age, race, household income, and household number of children, but not on sex. Specifically, the awareness-constrained are significantly younger than other nonvisitors and like the access-constrained have a larger number of children at home. The awareness-constrained are also much less likely than other nonvisitor respondents to be non-Hispanic whites or to have household incomes exceeding $\$ 100,000$. Regarding the intention to visit the Udvar-Hazy Center within the next three months, no significant differences between the clusters emerged.

(Table 4 here)

\section{DISCUSSION}

While the sampled non-visitors as a whole appear to be relatively unconstrained, it is through the cluster analysis approach that one is made aware of specific problems of awareness, time and access - or 'structural' factors as per the categories of Crawford, Jackson and Godbey (1991) - that do appear to significantly constrain about one-half of these non-visitors. Members of the awareness- and time-constrained clusters, in particular, cite these respective factors as major constraints with mean values above four and far above any 
other factor. In contrast, the access-constrained are in essence a 'multiconstrained' group that registers relatively high means on almost every factor. Aside from a high average number of children at home, the reasons for this response pattern are unclear. Less ambiguous is the (probably underrepresented) awareness-constrained respondents who have more children and lower incomes, and are more likely to be non-white and young. With regard to the statements, it is notable that lack of money is not a serious constraint for any of the clusters, whereas high parking fees are cited as the second most important constraint overall and the main factor for the access-constrained. It may be that local residents resent having to pay for parking, or perceive some level of resultant deception in relation to the promotion of the Center as a 'free entry' attraction.

With regard to managerial implications, a pessimistic interpretation of the data would posit that the proportion of local residents near the Udvar-Hazy Center that has never visited the facility corresponds to the threshold that has been identified empirically in other communities (that is, around one-half), and hence it may be difficult to attract the patronage of this 'hard-core' nonparticipant cohort. Crompton and Lamb (1986) corroborate this by arguing that it is easier to persuade previous museum-goers to make additional visits than it is to convince the nonparticipants to make an initial visit. Yet, this study has also yielded results which suggest that a strategy focused on attracting local residents who have not previously visited is far from an exercise in futility. 
First, it is worth reiterating that all the original constraint items produced a mean score below the midway value of 3.00 , indicating that most exercised only slight or no influence over respondent nonparticipation. The cluster analysis procedure, furthermore, revealed that a slight majority of respondents are 'minimally constrained' in concert with the overall pattern, with only the perception of a high parking fee approaching the status of an influential constraint. Second, while actual behavior cannot be extrapolated from expressions of intent, almost $38 \%$ of nonparticipants said that they intended to visit the Udvar-Hazy Center within the next three months. Whether they do or not, a high level of positive responsiveness is indicated that could be encouraged and enabled through effective promotion of the facility and its innovative displays. It may be that simple procrastination is an underlying factor for the minimally constrained, a possibility indicated in a study of local non-visitation at Congaree National Park near Columbia, South Carolina (Lawton \& Weaver, 2008). About one-half of the sample in this study were labeled as 'procrastinators' based on a 3.69 mean response (out of 5) on the statement 'I just haven't got around to it yet, but would like to visit'. If corroborated, then a marketing campaign with a 'why put it off any longer?' theme may prove effective. Concerted promotion (in Spanish as well as English), more generally, could attract the relatively small number of 'awareness constrained' residents for whom lack of knowledge about the Udvar-Hazy Center is the only constraint that is strongly to very strongly influential. It is not part of their awareness set of attractions, and hence is not available for consideration (Kotler \& Kotler, 1998). 
A third factor that supports the first two findings, but also acts potentially as a hindrance, is that the nonparticipants claim on average to visit four other museums or other cultural attractions on a yearly basis. As such, they are not hardcore nonparticipants in any broad sense, and may be open to Udvar-Hazy Center visitation as part of their broader pattern of visiting cultural attractions. Conversely, it may be that their desire to visit cultural attractions is already satisfied by their visits to those other sites, thereby making a visit to the UdvarHazy Center less attractive. This recognizes the capacity of individuals to negotiate their way through constraints in order to achieve desired levels of participation, in this case by visiting other cultural attractions (Jackson, Crawford, \& Godbey, 1993). Perhaps worthy of emulation is the strategy of a Kansas City suburb where greater visitation levels to local museums by residents was achieved by the introduction of interactive exhibits and programs focused on the evolving lifestyles of local residents (Kotler \& Kotler, 1998), though this might be difficult to achieve in an air and space thematic context.

Perhaps least amenable to strategies of negotiation or persuasion among the nonparticipants are the 'time constrained' $13.5 \%$ of respondents who like the awareness-constrained are a 'hardcore' segment by merit of producing at least one item that is strongly or very strongly influential, that is, with a mean above 4.00 (not having enough time, and having too many work commitments). Yet, all means possible should be taken to facilitate their negotiation of this constraint, since they have by far the highest household incomes $(69.2 \%$ over $\$ 100,000$, versus $15.0 \%$ for the awareness-constrained) and perceive all items unrelated to 
time, including the parking fee, as having little or no influence as a constraint. Such residents therefore have the potential to visit frequently, spend liberally during these visits, and provide ancillary support through donations and other mechanisms. A surprisingly finding is that members of this group are not significantly different than other groups in terms of overall annual number of museums visited, suggesting that priority may be given to other types of museum.

Like the time and awareness constrained, the larger group of accessconstrained respondents are remarkably focused on a distinctive parameter of constraint. Management is relatively ill-equipped to substantively influence associated limitations of distance, isolation and chronic traffic congestion, although the latter might be partially mitigated by extending hours of operation into periods when traffic congestion is less problematic. In contrast, management should consider substituting an equivalent group entry fee for the current parking fee, pending further research into visitor reactions. It is possible that entry fees are regarded as a legitimate cost associated with museum visitation, whereas parking fees are not, particularly within suburban settings.

Finally, issues of race and language pose a long-term challenge to healthy visitor flows from within the local community, given the rapid relative and absolute growth of the non-white and Hispanic population segments within the Virginia suburbs of Washington, DC. Alienation and other intrapersonal and interpersonal constraints are already indicated by the low participation of such groups in the survey, and subsequently by their dramatic over-representation 
within the nonparticipant cohort and the awareness-constrained cluster. Again, such segments need to be made aware of the Udvar-Hazy Center, but also to see themselves in associated exhibits and programs rather than only the dominant white, non-Hispanic society.

\section{CONCLUSION}

Continuing declines in visitation at the Udvar-Hazy Center pose an existential threat to a museum facility increasingly dependent on direct and indirect visitor revenue. An aggressive marketing strategy is therefore required that emphasizes audience development, and local community engagement in particular given the logic of market size, growth, prosperity and proximity, as well as spatial isolation from the tourist axis of central DC. Although nonparticipant levels of around $50 \%$ conform to other destinations and indicate an apparent hardcore of non-visitors, the latter as a group appear to be relatively unconstrained, show a surprisingly high intent to visit the Udvar-Hazy Center in the near future, and tend to patronize other cultural attractions. Thus, the apparently large proportion of possible 'procrastinators' among these may be amenable to a well-designed and executed marketing campaign that raises awareness of the Udvar-Hazy Center, and to structural and program amendments that emphasize the role of the local community in the air and space sector.

More specifically, the cluster analysis serves to further differentiate the nonparticipant sector in terms of salient constraints, and emphasizes the extent 
to which non-white and Hispanic residents are concentrated in the awarenessconstrained cluster. The study revealed that to be a small cluster, but this is perhaps more a reflection of the under-representation of such groups in the study than the actual situation within the rapidly changing population of the Virginia suburbs. The authors recognize the necessity for a follow-up study to focus specifically on the participation levels and constraints within the Hispanic and African-American communities.

\section{ACKNOWLEDGEMENTS}

This work was partially funded through a research grant made possible by the Dominion Foundation, USA. The authors are also grateful for the support received by the Smithsonian staff at the Steven F. Udvar-Hazy Center during the duration of this project, and for the participation of the local residents who took the time to complete the questionnaire.

\section{REFERENCES}

AAM. (2006). 2006 Museum Financial Information. Washington, DC: American Association of Museums.

Bryan, C. (2004). Revisiting museum visitation. Accessed from the Virginia Historical Society on August 24, 2007 at http://www.vahistorical.org/news/visitation.htm. 
Crawford, D., Jackson, E., \& Godbey, G. (1991). A hierarchical model of leisure constraints. Leisure Sciences, 13(4), 309-320.

Crompton, J., \& Lamb, C. (1986). Marketing Government and Social Services. New York: John Wiley \& Sons.

Dey, E. (1997). Working with low survey response rates: The efficacy of weighting adjustments. Research in Higher Education, 38(2), 215-227.

Dolnicar, S., \& Leisch, F. (2008). An investigation of tourists' patterns of obligation to protect the environment. Journal of Travel Research, 46, 381391.

Ezell, L. (2004). Building America's hangar: The design and construction of the Steven F. Udvar-Hazy Center. Washington D.C.: Smithsonian Institution, National Air and Space Museum.

Falk, J.H. (1993). Leisure Decisions Influencing African American Use of Museums. Washington, DC: American Association of Museums.

Fopp, M.A. (1997). Air and space museums come of age. Museum International, 49(3), 4-7.

Geissler, G., Rucks, C., \& Edison, S. (2006). Understanding the role of service convenience in art museum marketing: An exploratory study. Journal of Hospitality \& Leisure Marketing, 14(4), 69-87.

Graburn, N. (1998). A quest for identity. Museum International, 50(3), 13-18.

Hair, J., Anderson, R., Tatham, R., \& Black, W. (1995). Multivariate data analysis (4th ed.). Englewood Cliffs, NJ: Prentice-Hall. 
Hood, M.G. (1983, April). Staying away: Why people choose not to visit museums. Museum News, 50-57.

Hudson, K. (1998). The museum refuses to stand still. Museum International, $50(1), 43-50$.

Jackson, E. (Ed.). (2005). Constraints to leisure. State College, PA: Venture.

Jackson, E. (1988). Leisure constraints: A survey of past research. Leisure Sciences, 10(3), 203-215.

Jackson, E., Crawford, D., \& Godbey, G. (1993). Negotiation of leisure constraints. Leisure Sciences, 15(1), 1-11.

Kotler, N., \& Kotler, P. (1998). Museum strategy and marketing: Designing missions, building audiences, generating revenue and resources. San Francisco: Jossey-Bass.

Lawton, L., \& Weaver, D. (2008). Factors associated with non-visitation by area residents to Congaree National Park, South Carolina. Journal of Park \& Recreation Administration, 26(4), 66-82.

Mazanec, J., Grabler, K., Maier, G., \& Wöber, K. (1997). International City Tourism: Analysis and Strategy. London: Pinter/Cassell.

Mylonakis, J., \& Kendristakis, E. (2006). Evaluation of museums service quality: A research study of museums and galleries visitors' satisfaction. Tourism and Hospitality Management, 12(2), 37-54.

Nadirova, A., \& Jackson, E. (2000). Alternative criterion variables against which to assess the impacts of constraints to leisure. Journal of Leisure Research, 32, 396-405. 
Oppermann, M. (2000). Tourism destination loyalty. Journal of Travel Research, 39(1), 78-84.

Schouten, F. (1998). Professionals and visitors: Closing the gap. Museum International, 50(4), 27-30.

Singh, S., Timothy, D., \& Dowling, R. (Eds.) (2003). Tourism in destination communities. Wallingford, UK: CABI.

Smithsonian Institution. (2007a). Visits to the Smithsonian FY 2002 - FY 2006. Accessed March 10, 2007 at http://www.si.edu/about/budget/2008/46\%20Visitation\%20Chart.pdf. Smithsonian Institution. (2007b). Report to the Board of Regents: Fiscal year 2006. Accessed November 6, 2007 at http://72.14.209.104/search?q=cache:PG5xDBbKZ7oJ:www.si.edu/about/r egents/documents/FY2006AnnualReport.pdf+udvarhazy+center+visitation+decline\&hl=en\&ct=clnk\&cd=1\&gl=us .

Smithsonian National Air and Space Museum. (2003). National Air and Space Museum Opens the Steven F. Udvar-Hazy Center on Dec. 15, 2003. Press release SI-417-2003.

Tian, S., Crompton, J., \& Witt, P. (1996). Integrating constraints and benefits to identify responsive target markets for museum attractions. Journal of Travel Research, 35 (2), 34-45.

U.S. Census Bureau. (2006). 2006 American community survey. Accessed November 8, 2007 at http://www.census.gov/. 
Xie, P. (2006). Developing industrial heritage tourism: A case study of the proposed Jeep museum in Toledo, Ohio. Tourism Management, 27(6), $1321-1330$.

Yeh, J-T., \& Lin, C-L. (2005). Museum marking and strategy: Directors' perception and belief. Journal of American Academy of Business, 6, 279284.

\section{ABOUT THE AUTHORS}

Laura Lawton is a Senior Lecturer in the Department of Tourism, Leisure, Hotel and Sport Management within the Griffith Business School at Griffith University - Gold Coast Campus, Australia. Her research interests include: ecotourism, event management sustainability, and tourism management. Email: laura.lawton@griffith.edu.au Margaret (Maggie) Daniels is an Associate Professor in the School of Recreation, Health and Tourism within the College of Education and Human Development at George Mason University, USA. She has conducted extensive fieldwork in the areas of tourism planning and policy, supply resource promotion and event management pertaining to local economic development. 
Table 1. Visitors and non-visitors to Udvar-Hazy: Group comparisons

\begin{tabular}{|c|c|c|c|c|}
\hline Variable & $\begin{array}{l}\text { Have Visited } \\
n=228 \\
(54 \%)\end{array}$ & $\begin{array}{c}\text { Have Not } \\
\text { Visited } \\
n=194 \\
(46 \%)\end{array}$ & Test Value & $p$ \\
\hline Age (mean yrs.) & 49.7 & 52.3 & $t=-1.852$ & .065 \\
\hline $\begin{array}{c}\text { Sex: female } \% \\
\text { male } \%\end{array}$ & $\begin{array}{l}39.5 \\
60.5\end{array}$ & $\begin{array}{l}42.5 \\
57.5\end{array}$ & $x^{2}=.393$ & .531 \\
\hline $\begin{array}{l}\text { Race: White (non-Hispanic) } \\
\%\end{array}$ & 89.3 & 77.0 & & \\
\hline non-White $\%$ & 10.7 & 23.0 & $x^{2}=11.560$ & .001 \\
\hline $\begin{array}{r}\text { Household income } \\
<\$ 100,000 \% \\
>\$ 100,000 \%\end{array}$ & $\begin{array}{l}41.1 \\
48.9\end{array}$ & $\begin{array}{l}49.2 \\
50.8\end{array}$ & $x^{2}=2.544$ & .111 \\
\hline $\begin{array}{l}\text { No. of museums and/or } \\
\text { cultural attractions visited } \\
\text { on a yearly basis (mean) }\end{array}$ & $\begin{array}{c}5.28 \\
(\mathrm{SD}=4.92)\end{array}$ & $\begin{array}{c}4.05 \\
(\mathrm{SD}=4.36)\end{array}$ & $t=-2.659$ & .008 \\
\hline
\end{tabular}


Table 2. Reasons for not visiting Udvar-Hazy Center:

Ranked means for all non-visitors

\begin{tabular}{lc}
\hline Reason & Mean' \\
& \\
\hline I don't have enough time & 2.80 \\
The parking fee is too high & 2.72 \\
I have too many work commitments & 2.29 \\
Conflicting schedules with family/friends & 2.20 \\
The museum is not close to other attractions & 1.84 \\
Traffic around the Udvar-Hazy Center is bad & 1.82 \\
Planning a visit is difficult & 1.77 \\
My family/friends like to do other things & 1.76 \\
I don't know where the museum is located & 1.72 \\
The museum is too far from where I live & 1.70 \\
I have never heard of the museum & 1.58 \\
I have no interest in air and space history & 1.54 \\
It is hard to find the museum & 1.46 \\
I don't have enough money & 1.42 \\
I have no one to go with & 1.35 \\
I am in poor health & 1.24 \\
Physical barriers make visitation difficult & \\
I lack a means of transportation & 1.20 \\
' based on 5-point scale where 5 = 'very strong influence', 4 = 'strong influence', \\
3 = 'some influence', 2 = 'slight influence', and 1 = 'no influence' \\
2 item excluded from cluster analysis
\end{tabular}


Table 3. Reasons for not visiting Udvar-Hazy Center: Cluster comparisons ${ }^{1,3}$

\begin{tabular}{|c|c|c|c|c|}
\hline Item $^{2}$ & $\begin{array}{l}\text { Cluster } 1 \\
\text { Minimally- } \\
\text { constrained } \\
\mathrm{n}=101\end{array}$ & $\begin{array}{c}\text { Cluster } 2 \\
\text { Awareness- } \\
\text { Constrained } \\
\quad \mathrm{n}=22\end{array}$ & $\begin{array}{l}\text { Cluster } 3 \\
\text { Time-constrained } \\
n=26\end{array}$ & $\begin{array}{c}\text { Cluster } 4 \\
\text { Access- } \\
\text { constrained } \\
n=43\end{array}$ \\
\hline I don't have enough time & 2.29 & 2.55 & 4.35 & 3.19 \\
\hline The parking fee is too high & 2.65 & 2.23 & 1.54 & 3.86 \\
\hline I have too many work commitments & 1.67 & 2.36 & 4.27 & 2.49 \\
\hline $\begin{array}{l}\text { Conflicting schedules with } \\
\text { family/friends }\end{array}$ & $\overline{1.71}$ & 2.00 & 3.46 & 2.70 \\
\hline $\begin{array}{l}\text { The museum is not close to other } \\
\text { attractions }\end{array}$ & 1.49 & 1.41 & 1.23 & 3.28 \\
\hline $\begin{array}{l}\text { Traffic around the Udvar-Hazy } \\
\text { Center is bad }\end{array}$ & 1.42 & 1.55 & 1.54 & 3.09 \\
\hline Planning a visit is difficult & 1.44 & 1.59 & 2.12 & 2.44 \\
\hline $\begin{array}{l}\text { My family/friends like to do other } \\
\text { things }\end{array}$ & 1.53 & 1.50 & 2.04 & 2.23 \\
\hline $\begin{array}{l}\text { I don't know where the museum is } \\
\text { located }\end{array}$ & 1.21 & 2.64 & 1.12 & 2.84 \\
\hline $\begin{array}{l}\text { The museum is too far from where I } \\
\text { live }\end{array}$ & 1.35 & 1.32 & 1.42 & 2.91 \\
\hline I have never heard of the museum & 1.07 & 4.41 & 1.08 & 1.65 \\
\hline It is hard to find the museum & 1.10 & 1.27 & 1.00 & 2.70 \\
\hline I don't have enough money & 1.26 & 1.45 & 1.19 & 1.91 \\
\hline I lack a means of transportation & 1.07 & 1.18 & 1.00 & 1.51 \\
\hline \multicolumn{5}{|c|}{$\begin{array}{l}{ }^{3} \text { Bolded mean indicates significantly higher value than mean for other three clusters based on } \\
.05 \text { threshold of significance (based on Tukey's post hoc test). } \\
\text { Underlined mean indicates significantly lower value than mean for other three clusters based on } \\
.05 \text { threshold of significance (based on Tukey's post hoc test). }\end{array}$} \\
\hline
\end{tabular}


Table 4. Udvar-Hazy Center non-visitor cluster comparisons

\begin{tabular}{|c|c|c|c|c|c|}
\hline Variable & $\begin{array}{c}\text { Cluster } 1 \\
\text { Minimally- } \\
\text { constrained } \\
n=101\end{array}$ & $\begin{array}{c}\text { Cluster } 2 \\
\text { Awareness- } \\
\text { constrained } \\
n=22\end{array}$ & $\begin{array}{c}\text { Cluster } 3 \\
\text { Time- } \\
\text { constrained } \\
n=26\end{array}$ & $\begin{array}{c}\text { Cluster } 4 \\
\text { Access- } \\
\text { constrained } \\
n=43\end{array}$ & Test score \\
\hline Age (mean yrs.) ${ }^{1}$ & 52.0 & $\underline{39.4}$ & 49.5 & 49.9 & $F=5.171^{*}$ \\
\hline $\begin{array}{l}\text { Sex: male } \% \\
\quad \text { female } \%\end{array}$ & $\begin{array}{l}62.4 \\
37.6\end{array}$ & $\begin{array}{l}38.1 \\
61.9\end{array}$ & $\begin{array}{l}65.4 \\
34.6\end{array}$ & $\begin{array}{l}53.5 \\
46.5\end{array}$ & $x^{2}=5.514$ \\
\hline $\begin{array}{l}\text { Race: White (non-Hispanic) \% } \\
\text { non-White \% }\end{array}$ & $\begin{array}{l}88.0 \\
12.0\end{array}$ & $\begin{array}{l}33.3 \\
66.7\end{array}$ & $\begin{array}{l}76.9 \\
23.1\end{array}$ & $\begin{array}{l}71.4 \\
28.6\end{array}$ & $x^{2}=29.916^{*}$ \\
\hline $\begin{array}{r}\text { Household income } \\
<\$ 100,000 \% \\
>\$ 100,000 \%\end{array}$ & $\begin{array}{l}44.2 \\
55.8\end{array}$ & $\begin{array}{l}85.0 \\
15.0\end{array}$ & $\begin{array}{l}30.8 \\
69.2\end{array}$ & $\begin{array}{l}56.1 \\
43.9\end{array}$ & $x^{2}=15.509^{*}$ \\
\hline $\begin{array}{l}\text { No. of children in household } \\
<18 \text { (mean) }\end{array}$ & .62 & 1.33 & .62 & 1.07 & $F=3.679^{*}$ \\
\hline
\end{tabular}

